\title{
Non-canonical regulation of glutathione and trehalose biosynthesis characterizes non-Saccharomyces wine yeasts with poor performance in active dry yeast production
}

\author{
Esther Gamero-Sandemetrio ${ }^{1}$, Lucía Payá-Tormo ${ }^{1}$, Rocío Gómez-Pastor ${ }^{1,3}$, Agustín Aranda $^{1,2}$ and Emilia \\ Matallana ${ }^{1,2, *}$ \\ ${ }^{1}$ Department of Biotechnology, Institute for Agrochemistry and Food Technology, CSIC, Valencia, Spain. \\ ${ }^{2}$ Institute for Integrative Systems Biology I2SysBio, Universitat de València/CSIC, Valencia. Spain. \\ ${ }^{3}$ Present address: Department of Neuroscience, Medical School, University of Minnesota, Minneapolis, Minnesota, USA. \\ * Corresponding Author: \\ Emilia Matallana, Institute for Integrative Systems Biology, I2SysBio (Universitat de València-CSIC), C/ Catedràtic José Beltrán 2, \\ 46980-Paterna, Valencia, Spain; Tel: +34964544784; E-mail: emilia.matallana@uv.es
}

\begin{abstract}
Several yeast species, belonging to Saccharomyces and nonSaccharomyces genera, play fundamental roles during spontaneous must grape fermentation, and recent studies have shown that mixed fermentations, co-inoculated with $S$. cerevisiae and non-Saccharomyces strains, can improve wine organoleptic properties. During active dry yeast (ADY) production, antioxidant systems play an essential role in yeast survival and vitality as both biomass propagation and dehydration cause cellular oxidative stress and negatively affect technological performance. Mechanisms for adaptation and resistance to desiccation have been described for $S$. cerevisiae, but no data are available on the physiology and oxidative stress response of nonSaccharomyces wine yeasts and their potential impact on ADY production. In this study we analyzed the oxidative stress response in several nonSaccharomyces yeast species by measuring the activity of reactive oxygen species (ROS) scavenging enzymes, e.g., catalase and glutathione reductase, accumulation of protective metabolites, e.g., trehalose and reduced glutathione (GSH), and lipid and protein oxidation levels. Our data suggest that noncanonical regulation of glutathione and trehalose biosynthesis could cause poor fermentative performance after ADY production, as it corroborates the corrective effect of antioxidant treatments, during biomass propagation, with both pure chemicals and food-grade argan oil.
\end{abstract}

doi: $10.15698 /$ mic2018.04.624

Received originally: 25.09.2017;

in revised form: 13.01.2018,

Accepted 15.01.2018,

Published 26.01.2018.

Keywords: non-Saccharomyces yeasts, active dry wine yeasts, foodgrade argan oil, oxidative damage, antioxidant defense.
Abbreviations:
$A D Y$ - active dry yeast, $G R$ - glutathione reductase, GSH - reduced glutathione, GSSG - oxidized glutathione, ROS - reactive oxygen species.

\section{INTRODUCTION}

Grape must fermentation is a complex biochemical process in which diverse yeasts, including Saccharomyces and nonSaccharomyces species, play fundamental roles in transforming grape sugars into ethanol, carbon dioxide, and hundreds of other secondary products. Early fermentation stages are dominated by non-Saccharomyces yeasts that are gradually replaced with the species Saccharomyces cerevisiae, which takes over fermentation [1]. The dominance of non-Saccharomyces yeasts in early fermentation stages has a major impact on the aromatic composition and sensory properties of wine [2-4]. Consequently, many researchers have investigated the metabolic properties of various non-Saccharomyces yeast species and their potential applications in the wine industry [5-6] to thus determine a positive impact on the body and organoleptic quality of wines. Active dry yeast (ADY) is commonly used as an inoculum in wine fermentations, which leads to greater process control and consistent quality [7]. Recent studies have shown that mixed fermentations co-inoculated with $S$. cerevisiae and non-Saccharomyces strains can improve the analytical and aromatic profile of wines through metabolic interactions between different yeast species [3-4]. However, non-Saccharomyces ADY usually displays poor fermentative capacity, and the production process in molasses medium gives low biomass yields. Both biomass propaga- 
tion and dehydration in industrial ADY production of $S$. cerevisiae strains have been reported to cause cellular oxidative stress, and then negatively affect performance [810]. Therefore, antioxidant systems play an essential role in tolerance to drying. In $S$. cerevisiae, adaptation and resistance to desiccation include protection against oxidative stress through ROS scavenging enzymes, such as catalase and glutathione reductase, and protective metabolites, such as trehalose and reduced glutathione (GSH). However, the oxidative stress response in non-Saccharomyces species and its putative relevance for their low yield and fermentative efficiency after ADY production have not been studied. We recently identified a set of biochemical parameters (levels of oxidized glutathione and trehalose, and catalase and glutathione reductase activities), analyzed after dehydration, which allowed the prediction of physiologically relevant phenotypes for wine $S$. cerevisiae strains [11], and we demonstrated that a low level of oxidative defense characterizes deficiently performing strains. So the study of these parameters can help to define the antioxidant response of non-Saccharomyces strains, and to also find correlations with their resistance and performance during ADY production. Due to the interest of these yeast species as mixed starters with $S$. cerevisiae strains, the design of technologically affordable treatments for improving their performance as ADY would have important biotechnological implications for wine making [12-13]. Recently, we proposed using three pure antioxidant molecules (ascorbic, caffeic and oleic acids), and argan oil as a foodgrade natural antioxidant, in industrial processes that involve high cellular oxidative stress, such as the biotechnological production of dry starters [14]. L-ascorbic acid (vitamin C) acts as a reducing substrate for peroxidases [15]. $S$. cerevisiae strains synthesize the analog, erythroascorbate, which prevents apoptosis induced by pro-oxidants, increases the levels of GSH and lowers ROS levels [16]. Antibacterial, antiviral, anti-inflammatory, anticancer and antioxidant activities have been described for caffeic acid in several organisms [17-20]. At low doses, it suppresses lipid peroxidation [17] and blocks ROS [19]. Under exogenous oxidative stress, caffeic acid increases GSH levels and lowers ROS levels in S. cerevisiae [16]. Oleic acid supplementation in $S$. cerevisiae growth media can alleviate oxidative stress during must fermentation [21] as the lipid composition of the cell membrane modulates the activity of enzymes and membrane-associated transporter functions [22-23]. Finally, argan oil is an example of a natural product rich in antioxidants, which is now commercialized in both cosmetic and food grades, and displays antiproliferative, antidiabetic and cardiovascular risk-preventive effects [2425].

This study aimed to dissect the oxidative defense properties of several non-Saccharomyces wine yeast species during ADY production by determining the previously selected biomarkers and studying the protective antioxidant effects of pure chemicals and natural products. To do this, non-Saccharomyces yeasts were propagated on molasses supplemented, or not, with the aforementioned antioxidants, and were then dehydrated. The resulting ADY products were assayed for fermentative performance, biomass yield, the above-mentioned biomarkers, and also for effects on wine produced in mixed fermentations.

TABLE 1. Biomass yield, fermentative capacity and oxidatively damaged macromolecules in T73 (S. cerevisiae) and non-Saccharomyces wine yeast strains.

\begin{tabular}{|c|c|c|c|c|}
\hline Strain & Biomass yield $^{a}$ & $\begin{array}{c}\text { Fermentative } \\
\text { capacity }\left(\mathrm{mL} \mathrm{CO}_{2} / 10^{7}\right. \\
\text { cells })^{\mathrm{b}}\end{array}$ & $\begin{array}{c}\text { Lipid peroxidation } \\
\text { (pmol MDA/ mg } \\
\text { protein) }^{\mathrm{c}}\end{array}$ & $\begin{array}{l}\text { Protein carbonylation } \\
\qquad(\mathrm{Ci} / \mathrm{Pi})^{\mathrm{c}}\end{array}$ \\
\hline T73 & $18.42( \pm 0.28)$ & $10.52( \pm 0.30)$ & $26.85( \pm 2.04)$ & $23.26( \pm 1.38)$ \\
\hline C. stellata & $25.84( \pm 0.39)$ & $1.77( \pm 0.45)$ & $17.16( \pm 1.00)$ & $15.20( \pm 1.10)$ \\
\hline T. delbrueckii & $10.03( \pm 0.79)$ & $11.33( \pm 0.94)$ & $19.61( \pm 0.57)$ & $24.93( \pm 0.51)$ \\
\hline P. fermentans & $8.73( \pm 0.19)$ & $1.23( \pm 0.52)$ & $17.73( \pm 0.84)$ & $14.31( \pm 0.57)$ \\
\hline H. osmophila & $10.17( \pm 1.09)$ & $3.81( \pm 0.50)$ & $24.80( \pm 1.86)$ & $17.88( \pm 0.26)$ \\
\hline H. guilliermondii & $9.2( \pm 2.10)$ & $2.81( \pm 0.62)$ & $20.82( \pm 1.57)$ & $12.99( \pm 0.70)$ \\
\hline
\end{tabular}

${ }^{\text {a }}$ Cell growth after $24 \mathrm{~h}$ in the molasses medium at $30^{\circ} \mathrm{C}$, measured as $\mathrm{OD}_{600}$.

${ }^{\mathrm{b}}$ Fermentative capacity from ADY; measured in YPGF medium for $6 \mathrm{~h}$ at $30^{\circ} \mathrm{C}$.

${ }^{c}$ Lipid peroxidation and protein carbonylation from ADY. Protein carbonyl was expressed as $\mathrm{Ci} / \mathrm{Pi}$, where $\mathrm{Ci}$ is the protein carbonyl content quantified by an image analysis and $\mathrm{Pi}$ is total protein from coomassie-stained membranes.

*SD of three independent experiments in brackets. 


\section{RESULTS}

Deficient oxidative defenses in non-Saccharomyces species cause inappropriate fermentative performance for active dry wine yeast production

Five non-Saccharomyces wine yeast strains were selected according to their physiology and potential contribution to wine organoleptic properties, and were tested for performance during and after ADY production by assaying biomass yield and fermentation capacity in comparison to the efficient commercial S. cerevisiae wine strain T73 (Table 1). In general, non-Saccharomyces yeasts give low biomass yields, except for $C$. stellata whose performance was almost $50 \%$ higher than the control strain T73. Similar results were obtained for fermentative capacity, but in this case $T$. delbrueckii was the species that displayed better fermentative capacity, similarly to the control strain. In order to gain further information on the molecular causes of the physiological behavior of these wine yeasts, oxidative macromolecular damage markers were analyzed. As seen in Table 1, lipid peroxidation and protein carbonylation were not significantly higher for any of the five non-Saccharomyces species compared to the control strain, even both parameters were lower for most of them. H. osmophila proved similar to the control strain in lipid peroxidation terms, whereas $T$. delbrueckii did in protein carbonylation terms.

As the analyzed markers of lipid and protein oxidative damage did not provide clues about the molecular basis of non-Saccharomyces yeasts' suboptimal performance, we extended the study to other biochemical parameters, such as glutathione and trehalose levels, and the enzymatic activities of catalase and glutathione reductase (Table 2). In general, all the non-Saccharomyces yeasts displayed a low GSH/GSSG ratio compared to strain T73 in fresh cells (Table 2 ), which is a negative factor for a healthy cellular redox state [26]. These data suggest that regulation of glutathione biosynthesis in non-Saccharomyces wine yeasts might be a limiting factor for adaptation during biomass propagation compared to $S$. cerevisiae strains. This general differ- ence is not maintained after dehydration and only two of the non-Saccharomyces species displayed very low GSH/GSSG ratios in dry cells.

Regarding intracellular trehalose accumulation (Table 2 ), all the strains, except for $C$. stellata, showed that this protective metabolite accumulated after dehydration, as observed for the control strain. It is noteworthy that C. stellata displayed the lowest fermentative capacity in YPGF medium after rehydration. Although trehalose accumulation was induced by desiccation, these nonSaccharomyces species generally possess low levels of trehalose compared to the T73 control strain, which could be related to their generally poor performance during ADY production, where $T$. delbrueckii was the only exception, and also the strain that displayed the highest fermentative capacity (Table 1 ).

Regarding antioxidant enzymes, Table 2 shows the variation in the levels of glutathione reductase (GR) and catalase activities in dry versus fresh cells. In general terms, the desiccation-induced changes in both enzymatic activities did not provide a good correlation with the physiological parameters. For GR activity in the different nonSaccharomyces strains, it did not correlate with the GSH/GSSG ratios (Table 1), which could reinforce the hypothesis of the deficient, or different, regulation of glutathione metabolism in these yeast species. For catalase, although no large differences in the ratios between activity in dry and fresh cells were observed, it is worth stressing the high values of activity detected in both states for P. fermentans (fresh 30.77 and dry $48.39 \mathrm{U} / \mathrm{mg}$ protein; not shown), and specially for $C$. stellata (fresh 159.2 and dry $223.68 \mathrm{U} / \mathrm{mg}$ protein), compared to strain T73 (fresh 8.44 and dry $31.72 \mathrm{U} / \mathrm{mg}$ protein). The very marked catalase activity in fresh cells and the further induction after dehydration in $C$. stellata and $P$. fermentans could be related to their low fermentative capacity (Table 1). T. delbrueckii had moderate catalase activity in fresh cells (13.27 $\mathrm{U} / \mathrm{mg}$ protein), which even reduced (3.49 $\mathrm{U} / \mathrm{mg}$ protein) after dehydration. This suggests lower oxidative stress

TABLE 2. Biomarkers of the redox state in ADY from T73 (S. cerevisiae) and non-Saccharomyces wine yeast strains.

\begin{tabular}{|c|c|c|c|c|c|c|}
\hline \multirow{2}{*}{ Strain } & \multicolumn{2}{|c|}{ GSH/GSSG (nmol/mg cell) } & \multicolumn{2}{|c|}{ Trehalose ( $\mu \mathrm{g} / \mathrm{mg}$ cells) } & \multirow{2}{*}{$\begin{array}{c}\text { GR } \\
\text { (dry/fresh) }\end{array}$} & \multirow{2}{*}{$\begin{array}{c}\text { CAT } \\
\text { (dry/fresh) }\end{array}$} \\
\hline & Fresh cells & Dry cells & Fresh cells & Dry cells & & \\
\hline T73 & $98.18( \pm 5.12)$ & $14.24( \pm 1.12)$ & $85.24( \pm 0.79)$ & $149.57( \pm 0.12)$ & $0.61( \pm 0.03)$ & $3.76( \pm 0.09)$ \\
\hline C. stellata & $31.65( \pm 5.24)$ & $16.87( \pm 8.56)$ & $41.43( \pm 2.13)$ & $14.02( \pm 0.15)$ & $0.40( \pm 0.05)$ & $1.4( \pm 0.06)$ \\
\hline T. delbrueckii & $37.56( \pm 5.78)$ & $1.99( \pm 1.27)$ & $7.21( \pm 0.55)$ & $80.33( \pm 7.79)$ & $2.57( \pm 0.03)$ & $0.26( \pm 0.03)$ \\
\hline P. fermentans & $37.59( \pm 4.51)$ & $12.47( \pm 3.74)$ & $2.33( \pm 0.08)$ & $37.35( \pm 0.59)$ & $0.43( \pm 0.01)$ & $1.57( \pm 0.09)$ \\
\hline H. osmophila & $75.41( \pm 10.4)$ & $6.95( \pm 2.77)$ & $5.14( \pm 0.41)$ & $17.67( \pm 2.07)$ & $3.30( \pm 0.04)$ & $2.13( \pm 0.04)$ \\
\hline H. guilliermondii & $23.02( \pm 5.79)$ & $13.75( \pm 1.97)$ & $3.67( \pm 0.08)$ & $8.53( \pm 097)$ & $1.37( \pm 0.05)$ & $3.98( \pm 0.06)$ \\
\hline
\end{tabular}

*SD of three independent experiments in brackets. GR (Glutathione reductase); CAT (Catalase). 
compared to the other strains, which could be consistent with its high fermentative capacity.

Enhancement of the oxidative stress response by antioxidants improves biomass yield but not fermentative efficiency

Three pure antioxidant molecules (ascorbic acid, caffeic acid and oleic acid), previously selected for their ability to improve fermentative performance in $S$. cerevisiae wine strains [14], were supplemented in molasses medium during biomass propagation to further investigate the relevance of the oxidative stress response and adaptation in these non-Saccharomyces wine yeasts, and to check their potential protective effects on fermentative performance in winemaking.

The individual effects of each antioxidant molecule on the physiological and biochemical parameters for the five strains under study and of the control T73 strain are shown in Table 3 where the value of each parameter is shown in relation to the data when antioxidants are absent for dry cells in Tables 1 and 2, except for biomass yield which is always given only in fresh cells. The three antioxidants generally increased biomass yields, with similar values for all the non-Saccharomyces, and also for the control S. cerevisiae strain T73. As for their action on fermentative capacity, the strongest positive effect was observed with the three antioxidants for $C$. stellata (3.7-fold in ascorbic acid; 3-fold in caffeic acid; 5-fold in oleic acid) and $\mathrm{H}$. osmophila (3-fold in ascorbic acid; 3.1-fold in caffeic acid; 4fold in oleic acid). Other strain or antioxidant-dependent effects were also observed as the positive effect of oleic acid of the fermentative capacity of $T$. delbrueckii (1.91fold).

Lipid peroxidation was slightly diminished by treatment with any of the antioxidants in all the non-Saccharomyces species, and also in the T73 control strain, except for oleic acid which did not reduce this molecular damage in the S. cerevisiae strain.

Once again, the antioxidants effects of protein carbonylation were not homogeneous, and both antioxidant and strain-dependent behaviors were observed. However, the level of this oxidative damage to proteins slightly increased with the antioxidant treatments in four of the five non-Saccharomyces yeasts, these being $C$. stellata, $P$. fermentans, and both Hanseniaspora species. All the antioxidants diminished protein carbonylation in $T$. delbrueckii.

The effect on the ratio between reduced and oxidized glutathione was similar for all three antioxidants, and for all the analyzed yeasts. A slightly increase in the GSH/GSSG ratio was observed, which suggests that the protective

TABLE 3. Effect of ascorbic acid, caffeic acid or oleic acid supplementations on yeast performance and oxidative response. Data relative to those in Tables 1 and 2.

\begin{tabular}{|c|c|c|c|c|c|c|}
\hline & $T 73$ & C. stellata & T. delbrueckii & P. fermentans & H. osmophila & H. guilliermondii \\
\hline \multirow{3}{*}{ Biomass yield } & $1.16 \pm 0.03$ & $0.99 \pm 0.07$ & $2.83 \pm 0.08$ & $2.11 \pm 0.01$ & $1.14 \pm 0.08$ & $2.64 \pm 0.01$ \\
\hline & $1.54 \pm 0.01$ & $1.22 \pm 0.03$ & $2.06 \pm 0.09$ & $2.37 \pm 0.03$ & $2.99 \pm 0.05$ & $2.79 \pm 0.01$ \\
\hline & $1.81 \pm 0.02$ & $1.38 \pm 0.02$ & $2.81 \pm 0.05$ & $3.22 \pm 0.01$ & $2.46 \pm 0.02$ & $3.33 \pm 0.05$ \\
\hline \multirow{3}{*}{ Fermentative Capacity } & $2.11 \pm 0.01$ & $3.7 \pm 0.05$ & $0.96 \pm 0.08$ & $1.00 \pm 0.05$ & $3.04 \pm 0.08$ & $1.66 \pm 0.06$ \\
\hline & $0.86 \pm 0.02$ & $3.06 \pm 0.01$ & $1.07 \pm 0.01$ & $1.08 \pm 0.01$ & $3.14 \pm 0.07$ & $1.61 \pm 0.05$ \\
\hline & $0.86 \pm 0.01$ & $5.03 \pm 0.02$ & $1.91 \pm 0.01$ & $0.58 \pm 0.01$ & $4.08 \pm 0.03$ & $1.88 \pm 0.01$ \\
\hline \multirow{3}{*}{ Lipid Peroxidation } & $0.87 \pm 0.05$ & $0.93 \pm 0.04$ & $0.69 \pm 0.01$ & $0.55 \pm 0.01$ & $0.79 \pm 0.03$ & $0.39 \pm 0.01$ \\
\hline & $0.79 \pm 0.02$ & $0.88 \pm 0.02$ & $1.06 \pm 0.01$ & $1.07 \pm 0.03$ & $0.95 \pm 0.02$ & $1.02 \pm 0.01$ \\
\hline & $1.08 \pm 0.01$ & $0.82 \pm 0.02$ & $0.69 \pm 0.01$ & $0.65 \pm 0.01$ & $0.76 \pm 0.02$ & $0.79 \pm 0.03$ \\
\hline \multirow{3}{*}{ Protein Carbonylation } & $1.04 \pm 0.05$ & $1.05 \pm 0.07$ & $0.54 \pm 0.04$ & $1.27 \pm 0.06$ & $1.44 \pm 0.07$ & $1.55 \pm 0.09$ \\
\hline & $1.16 \pm 0.01$ & $1.19 \pm 0.01$ & $0.81 \pm 0.02$ & $1.33 \pm 0.03$ & $1.29 \pm 0.01$ & $1.02 \pm 0.01$ \\
\hline & $1.03 \pm 0.02$ & $1.04 \pm 0.01$ & $0.71 \pm 0.01$ & $0.96 \pm 0.03$ & $1.29 \pm 0.05$ & $1.47 \pm 0.04$ \\
\hline \multirow{3}{*}{ GSH/GSSG } & $1.13 \pm 0.01$ & $1.2 \pm 0.02$ & $1.19 \pm 0.01$ & $1.28 \pm 0.01$ & $1.13 \pm 0.01$ & $1.65 \pm 0.02$ \\
\hline & $1.24 \pm 0.02$ & $2.0 \pm 0.02$ & $1.01 \pm 0.01$ & $1.33 \pm 0.05$ & $0.85 \pm 0.02$ & $1.44 \pm 0.01$ \\
\hline & $1.38 \pm 0.02$ & $1.57 \pm 0.04$ & $0.93 \pm 0.01$ & $1.47 \pm 0.01$ & $0.90 \pm 0.02$ & $1.66 \pm 0.01$ \\
\hline \multirow{3}{*}{ Trehalose } & $6.28 \pm 0.21$ & $65.08 \pm 0.25$ & $3.31 \pm 0.01$ & $0.35 \pm 0.11$ & $0.07 \pm 0.01$ & $0.30 \pm 0.01$ \\
\hline & $3.66 \pm 0.02$ & $54.86 \pm 2.11$ & $2.00 \pm 0.01$ & $0.46 \pm 0.01$ & $2.76 \pm 0.05$ & $2.83 \pm 0.02$ \\
\hline & $4.34 \pm 0.02$ & $44.6 \pm 1.01$ & $2.21 \pm 0.01$ & $0.93 \pm 0.01$ & $1.80 \pm 0.04$ & $4.18 \pm 0.06$ \\
\hline \multirow{3}{*}{$\mathrm{GR}_{\mathrm{ADY}} / \mathrm{GR}_{\text {BIOMASS }}$} & $1.77 \pm 0.02$ & $6.82 \pm 0.04$ & $0.92 \pm 0.02$ & $2.97 \pm 0.01$ & $0.26 \pm 0.01$ & $0.39 \pm 0.01$ \\
\hline & $2.68 \pm 0.05$ & $5.35 \pm 0.06$ & $1.47 \pm 0.04$ & $8.65 \pm 0.05$ & $0.57 \pm 0.01$ & $0.13 \pm 0.02$ \\
\hline & $3.82 \pm 0.05$ & $5.97 \pm 0.06$ & $1.50 \pm 0.02$ & $2.86 \pm 0.03$ & $0.37 \pm 0.01$ & $0.39 \pm 0.01$ \\
\hline \multirow{3}{*}{$\mathrm{CAT}_{\mathrm{ADY}} / \mathrm{CAT}_{\text {BIOMASS }}$} & $0.33 \pm 0.04$ & $2.08 \pm 0.08$ & $1.80 \pm 0.01$ & $0.86 \pm 0.07$ & $0.25 \pm 0.02$ & $0.18 \pm 0.09$ \\
\hline & $0.26 \pm 0.01$ & $1.64 \pm 0.03$ & $1.03 \pm 002$ & $0.54 \pm 0.01$ & $0.33 \pm 0.01$ & $0.48 \pm 0.02$ \\
\hline & $0.54 \pm 0.02$ & $3.56 \pm 0.05$ & $1.16 \pm 0.02$ & $1.94 \pm 0.02$ & $0.32 \pm 0.01$ & $0.01 \pm 0.01$ \\
\hline
\end{tabular}

*SD of three independent experiments in brackets. 
effect improves the redox cellular state by elevating the GSH level and/or diminishing GSSG levels and, therefore, also oxidative stress.

The effects of ascorbic, caffeic and oleic acids on trehalose levels indicated two extreme responses in the two worse performing species in fermentative capacity terms: those of $C$. stellata and $P$. fermentans. $C$. stellata displayed an anomalous reduction in trehalose levels after dehydration (Table 2), which was reversed by the treatment with antioxidants (Table 3 ), which could explain the increased fermentative capacity produced in this yeast by the three compounds. $P$. fermentans, however, showed significantly increased trehalose accumulation during dehydration ( $\mathrm{Ta}$ ble 2), and the antioxidant treatments diminished it (Table $3)$, with very little effect on fermentative capacity. The trehalose accumulation of the two Hanseniaspora species, also characterized by their low fermentative capacity, was affected differentially by the three antioxidants, and no correlation was found between the trehalose level and the effect on fermentative capacity.

Finally, GR activity after dehydration was increased by all the treatments for the two non-Saccharomyces yeasts which displayed poor induction by dehydration (see Table 2 ), with different effects noted on the fermentative capaci- ty of $C$. stellata and $P$. fermentans, where the former improved, but not the latter. In the two Hanseniaspora species, the three antioxidants lowered the GR activity ratio between dry and fresh cells, which was relatively high in their absence (Table 2). The mildest effect of the three antioxidants on catalase activity was given for $T$. delbrueckii, the only species that showed lower activity after dehydration (Table 2), whereas all the other yeasts, except for $C$. stellata, lowered the ratio of the activity between dry and fresh cells under antioxidant treatment. Once again, no clear correlation with fermentative capacity was found for any individual antioxidant treatment.

Argan oil supplementation mimics the beneficial effects and the biomarkers patterns of individual antioxidant treatments

Argan oil was selected as a natural compound given its high content in ascorbic, caffeic and oleic acids, and because it improves both biomass yield and fermentative performance in ADY for $S$. cerevisiae wine strains [14].

Supplementation of molasses with $6 \mathrm{mg} / \mathrm{mL}$ of argan oil for biomass propagation increased the fermentative capacity in ADY for the control strain T73 and C. stellata, and especially for $H$. osmophila (Figure 1B). However, biomass
A
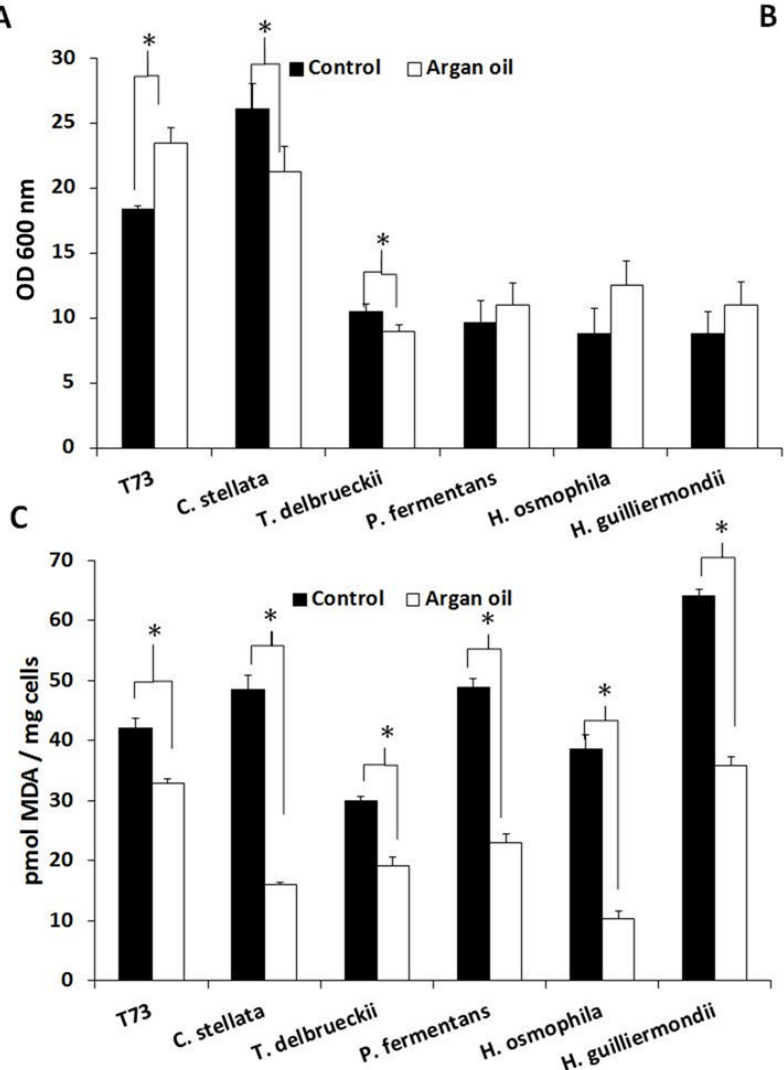

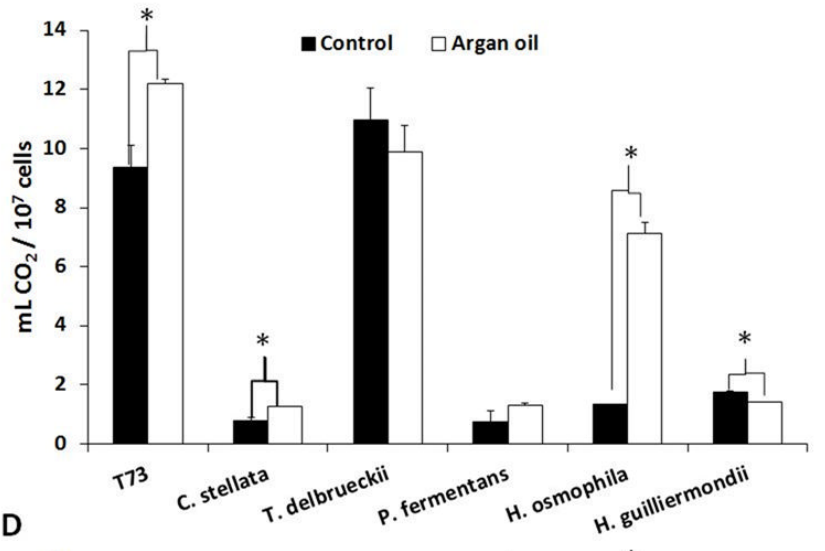

D

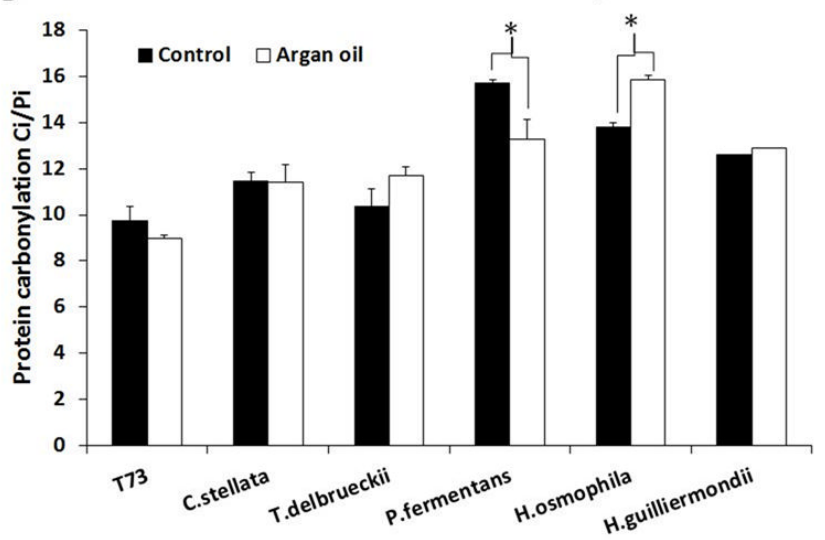

FIGURE 1: Effects of argan oil supplementation on physiological performance and oxidative damage. (A) Biomass yield, measured as OD at 600 $\mathrm{nm}$. (B) Fermentative capacity measured as the volume of $\mathrm{CO}_{2}$ produced per $10^{7}$ dry cells. (C) Lipid peroxidation in dry cells was expressed as the amount of MDA per mg of cells. (D) Protein carbonyl in dry cells was expressed as $\mathrm{Ci} / \mathrm{Pi}$, where $\mathrm{Ci}$ is the protein carbonyl content quantified by an image analysis and $\mathrm{Pi}$ is the total protein from coomassie-stained membranes. Error bars correspond to the SD value of three independent experiments. $\left({ }^{*}\right)$ significantly differed from the control (non-supplemented molasses) with $p<0.05$. 
yield clearly improved only in strain T73 (Figure 1A). Unlike the individual antioxidant treatments, argan oil supplementation generally protected lipid peroxidation (Figure 1C), with $H$. osmophila being the species for which this protection was greater. Argan oil supplementation did not significantly affect protein carbonylation (Figure 1D), but for $P$. fermentans and $H$. osmophila, contrary effects were observed, and no correlation was found with biomass yield or fermentative capacity.

The aforementioned predictive biomarkers were also analyzed for the ADY obtained with argan oil supplementation (Figures 2 and 3). Overall, the trehalose levels (Figure $2 A$ ) increased for all the strains and the GSSG levels lowered (Figure $3 \mathrm{~A}$ ). According to the data of both total glutathione and the GSH/GSSG ratio (Figure $3 B$ and $3 C$ ), argan oil would stimulate glutathione synthesis in all the nonSaccharomyces yeasts, except for C. stellata. Greater induction of GR activity (Figure 2B) was also observed, except for $T$. delbrueckii, which also had the lowest GSSG levels. As for the effects on catalase activity (Figure 2C), argan oil treatment only lowered catalase induction after desiccation in the Hanseniaspora species, and also in the control T73 strain.

Given the difficulty to simultaneously compare the effects on all the strains and parameters, a statistical principal component analysis (PCA) was performed and the 2dimensional graph (2D-plot) was used to better define the effect of argan oil supplementation on the physiological and oxidative stress parameters (Figure 4). As we can see, the argan oil-treated samples appear on the left of the graph and directly correlate with further increases, compared to the control situation, of the following parameters: induction of GR activity, fermentative capacity, trehalose levels and biomass production. An inverse correlation can also be seen with these parameters: induction of catalase activity, GSSG levels and lipid peroxidation to fermentative capacity. More specifically, we can identify the main effect exerted by argan oil supplementation on each strain, where: the $P$. fermentans and Hanseniaspora species would further increase their GR activity; the trehalose levels of $C$. stellata would increase; $T$. delbrueckii would be associated with both induction of GR activity and trehalose levels. These results also correlate with the data observed in the experiments shown in Figures 1 and 2.

Argan oil supplementation in ADY production improves $H$. osmophila viability during alcoholic fermentation of natural must

As molasses supplementation with argan oil has beneficial effects on the fermentative capacity of $\mathrm{H}$. osmophila ADY (Figure 1B), we decided to check whether it would also influence the behavior of this ADY when used for winemaking on natural must, as this species is of much enological interest thanks to its contribution with positive flavor compounds.

Figure 5 shows the sugar consumption and viability profiles for control strain T73 (Panels A and B) and H. osmophila (Panels $C$ and $D$ ) during pure culture vinifica-
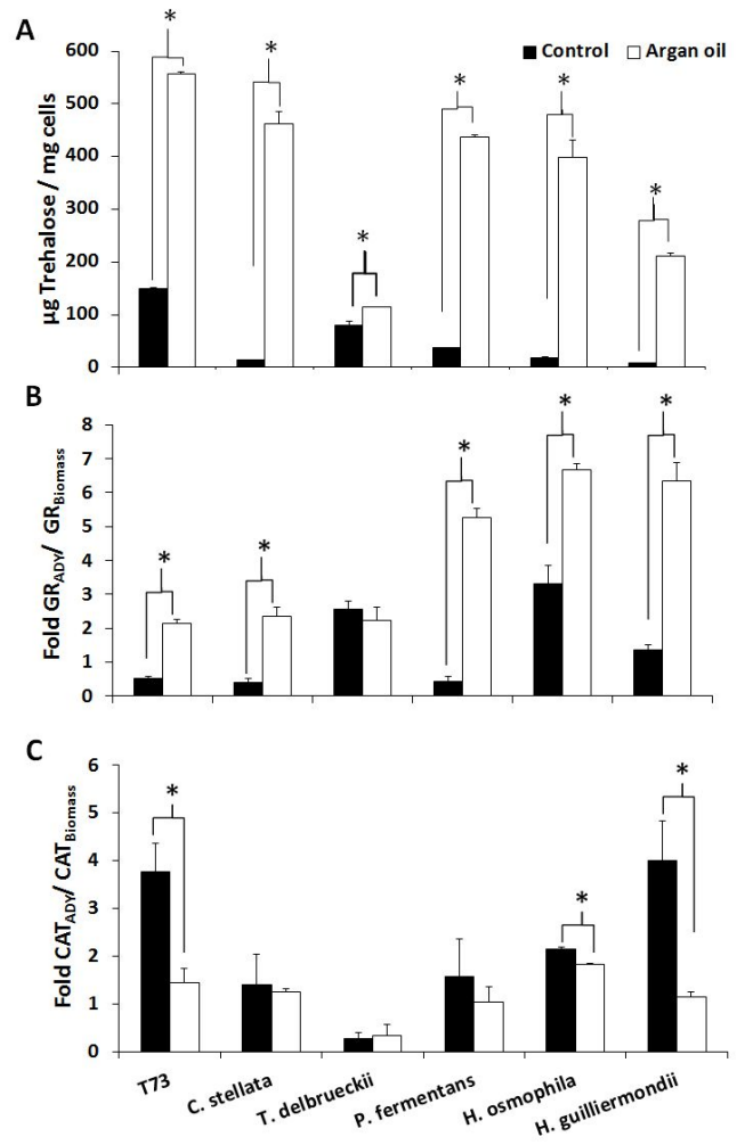

FIGURE 2: Analysis of the predictive biomarkers in ADY after argan oil supplementation during biomass propagation. (A) Trehalose content after drying. (B) Increment in glutathione reductase (GR) activity after drying. (C) Increment in catalase activity after drying. Error bars correspond to the SD of three independent experiments. $\left({ }^{*}\right)$ significantly differed from the control with a $p<$ 0.05 .

tions. As we can see for both species, no differences in sugar consumption are observed between the ADY obtained by growth in standard molasses and the argan oilsupplemented molasses (Figure 5, Panel A and C). However, the control S. cerevisiae strain T73 (Figure 5A) consumed sugars faster than non-Saccharomyces species (Figure $5 C$ ), as it is observed during the first days and also in time to complete sugar consumption. This observation is in agreement with literature, where lower fermentative power has been generally described for non-Saccharomyces yeasts [7]. The viability of the T73 control strain during wine fermentation was not affected by previously propagating the biomass for ADY production in the argan oil-supplemented molasses (Figure 5B), but it was improved by 1.8 -fold for $H$. osmophila (Figure 5D). 
A

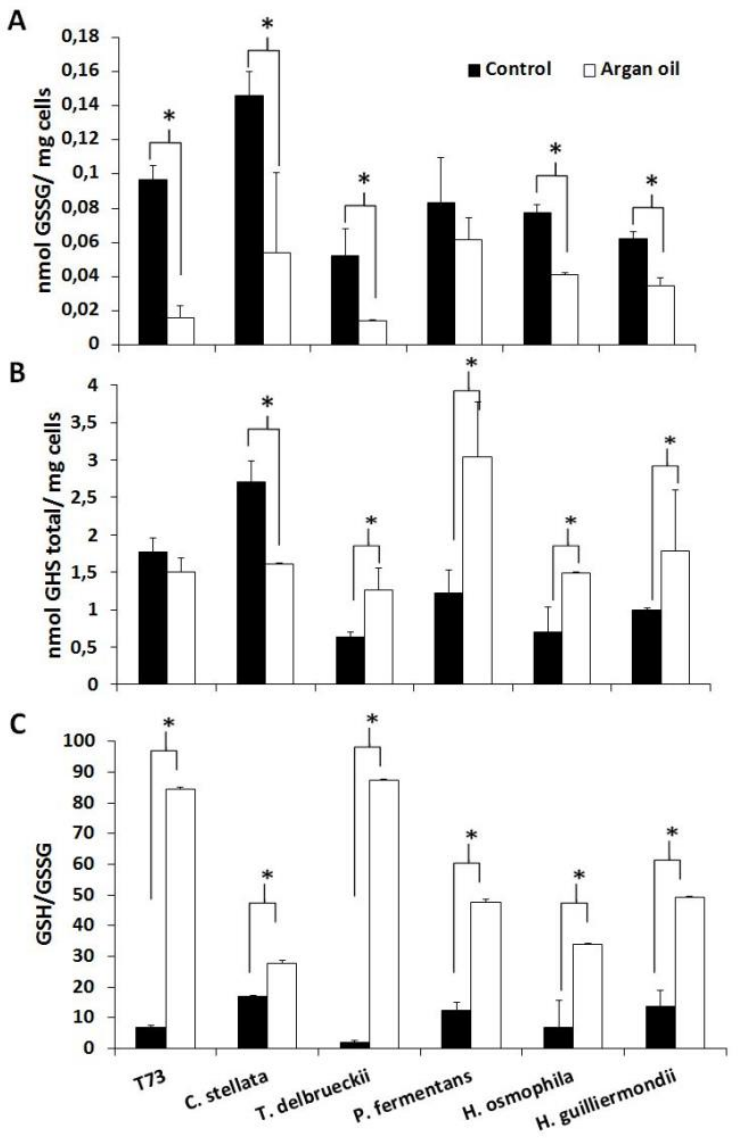

FIGURE 3: Analysis of the glutathione levels in ADY after argan oil supplementation during biomass propagation. (A) Oxidized glutathione after drying. (B) Total glutathione after drying. (C) The GSH/GSSG ratio after drying. Error bars correspond to the SD of three independent experiments. $\left({ }^{*}\right)$ significantly differed from the control with a $p<0.05$.

Argan oil supplementation in ADY production does not affect organoleptic and aromatic profiles in the mixed fermentation carried out by $S$. cerevisiae and H. osmophila strains

As mentioned in the introduction, non-Saccharomyces wine yeast provides greater complexity in aroma and flavor in wines, [27]. In order to check the putative effects of argan oil supplementation on this advantageous property, mixed multi-starter wine fermentations were designed using $S$. cerevisiae T73 ADY, both from standard (control) and the argan oil-supplemented molasses (argan), and $H$. osmophila ADY from the argan oil-supplemented molasses.

Figure 5, Panel E, shows the sugar consumption profiles for the mixed multi-starter vinifications. Sugar consumption in the initial fermentation phases was faster in mixed multi-starter winemaking, probably because both yeast species act from the beginning and contribute to sugar degradation. Moreover, mixed fermentation was completed after 10 days, as were the T73-conducted fermentations.
Organoleptic and sensorial characterization was also carried out for the pure culture and the mixed multistarter vinifications to identify any potential positive or detrimental effects of argan oil supplementation during ADY production. The levels of ethanol, glycerol and acetic acid, and the profile of the volatile compounds (Table 4), were determined in the final wine products.

Ethanol and glycerol levels were similar for all the analyzed vinification products, and always fell within the standard range in wine, although ethanol production is generally higher after argan oil treatment, which is consistent with the improvement in fermentative capacity. However, acetic acid accumulation was clearly reduced for both pure culture vinifications using the argan-treated ADY, and this effect was particularly relevant for that conducted by control strain T73 ADY as the acetic acid level produced when the starter was obtained in standard molasses was much higher $(0.14 \mathrm{~g} / \mathrm{L})$ than obtained in the argan oilsupplemented molasses $(0.004 \mathrm{~g} / \mathrm{L})$. Interestingly, the mixed vinification, where the $H$. osmophila ADY came from the argan oil-supplemented molasses, maintained adequate acetic acid levels $(0.18 \mathrm{~g} / \mathrm{L})$, similar to the value obtained in the pure culture T73 vinifications.

The profile of volatile compounds (Table 4) showed that argan oil supplementation in ADY production diminished the accumulation of undesirable ethyl acetate in the $H$. osmophila pure culture fermentation, and also in the mixed multi-starter fermentations. Although mixed multistarter fermentations reached higher ethyl acetate levels than the T73 fermentation, these levels fell within the range of values to confer wine pleasant aromas as ethyl acetate provides desirable characteristics from 150-200 mg/L.

Regarding desirable higher alcohol acetate esters ( $\mathrm{Ta}$ ble 4), argan oil supplementation had very little effect on their production, and the positive desirable contribution of $H$. osmophila on acetate esters accumulation was not found in the mixed multistarter vinifications.

Accumulation of higher alcohols, such as isobutanol, isoamyl alcohol and 2-phenylethanol (Table 4), were increased by the argan oil supplementation in the pure fermentations, but not in the mixed fermentations. However, their basal levels under these conditions were higher than in the pure culture fermentations.

Finally, the fatty acid esters group, such as caproate, ethyl caprylate and ethyl caprate, was measured (Table 4). In general, argan oil treatment increased their levels in the pure cultures vinifications, but not in the mixed fermentation.

\section{DISCUSSION}

In the last few years, several studies that have evaluated the use of controlled mixed fermentations, using Saccharomyces and different non-Saccharomyces wine yeast species [2, 28-29], have concluded that such mixed fermentations are a feasible way to improve complexity and to enhance specific characteristics of wines [27]. The consequent need for non-Saccharomyces ADY production has revealed new technological challenges as this industrial 


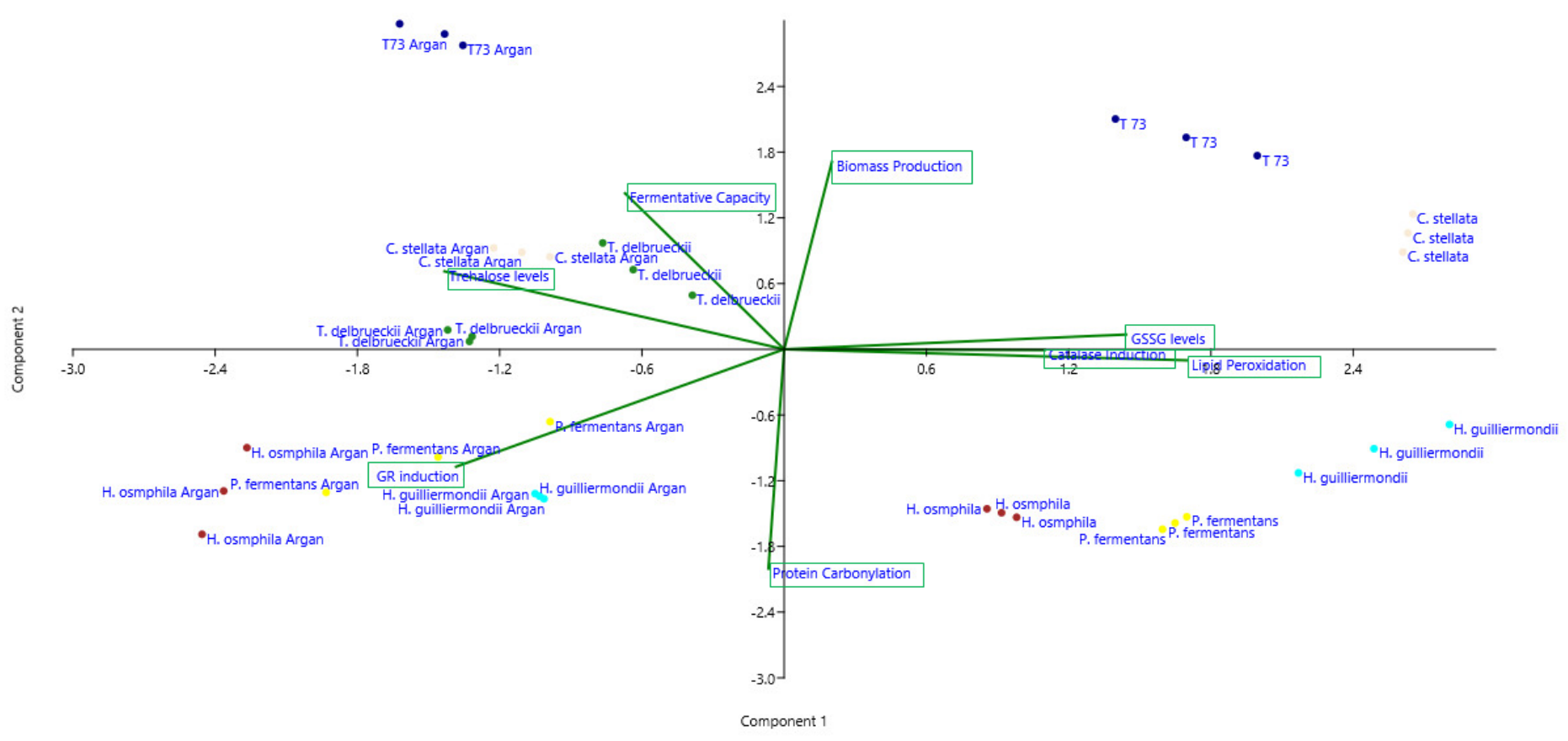

FIGURE 4: Principal components (PCA) statistical analysis of the argan oil effects on the physiological and biochemical biomarkers with represented total variance of $\mathbf{7 9} \%$. Component 1 reflects $39.55 \%$ total variance (with a positive correlation with biomass yield, trehalose levels and glutathione reductase activity) and Component 2 reflects $30.45 \%$ total variance (with a positive correlation with GSSG levels). Lines belong to the variance of the dependent variables or the biochemical biomarkers measured (biomass yield, fermentative capacity, lipid peroxidation, protein carbonylation, protective metabolites and enzymatic activities) arranged in two dimensions according to Components

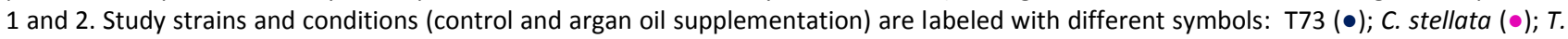
delbrueckii $(\bullet)$; P. fermentans $(\bullet)$; H. osmophila $(\bullet)$; and H. guilliermondii $(\bullet)$, and are associated with the dependent variable, which differs from the other strains and conditions.

process has been historically designed and optimized for high biomass yields with $S$. cerevisiae strains. Negative effects on the viability and vitality of $S$. cerevisiae cells have been described [30], largely due to the oxidative damage of cellular components caused by ROS production [31]. We recently described how wine $S$. cerevisiae strains with naturally high antioxidant defenses underwent less oxidative damage and displayed high fermentative capacity after dehydration, and we tested easily predictable markers for this biotechnologically relevant behavior [11]. We also showed that molasses supplementation with pure antioxidant molecules (ascorbic, caffeic or oleic acids), or with food-grade argan oil, diminished the oxidative damage associated with ADY production through different molecular mechanisms [14].

This work aimed to characterize the physiological properties of five non-Saccharomyces oenological yeasts species during the ADY production process to obtain biochemical and cellular clues to their industrial performance. We analyzed their physiological and biochemical oxidative state after biomass propagation and dehydration, and tested the effects of antioxidants molasses supplementation for ADY production.
In general, the analyzed non-Saccharomyces yeasts display poor global performance after ADY production, a trait that can be related to some markers for deficient oxidative defense, such as a low intracellular GSH/GSSG ratio and low catalase activity induction, and also to low trehalose accumulation in fresh cells, and particularly in dry cells. However, the correlation found between antioxidant defenses and fitness after dehydration was not as clear as we previously described for S. cerevisiae wine strains [14], which suggests that these non-Saccharomyces species have additional physiological determinants. We found that C. stellata biomass yield was higher than the $S$. cerevisiae strain (T73), which could be because it is a largely aerobic and fructophilic yeast [32-34] that can consume both glucose and fructose efficiently to result in higher biomass yields, whereas low oxidative defenses would mainly affect it resistance to dehydration, which would explain its low fermentative capacity. The described fermentative metabolism of $T$. delbrueckii agreed with its observed high fermentative capacity, and even reached a low biomass yield due to the oxidative stress associated with industrial yeast propagation [8]. Nonetheless in 2003, the first commercial release by Chr. Hansen (https://www.chr-hansen.com) of $T$. delbrueckii was yeast blends with $S$. cerevisiae andK. ther- 
motolerans, and subsequently on its own and also by Laffort (https://www.laffort.com/es) and Lallemand Inc (http://www.lallemand.com) two other T. delbrueckii strains are also available, which indicates the interest in carefully selected and tested non-Saccharomyces yeasts.

Ascorbic, caffeic and oleic acids supplementation improved oxidative response, but only increased the biomass yield in non-Saccharomyces species. It is known that ascorbic acid stimulates mitochondrial glycerol 3-phosphate dehydrogenase [35] to allow glycerol rerouting to glycolysis. Moreover, ascorbic acid has been shown to efficiently scavenge ROS, protect membrane lipids against peroxidation [36], increase low glutathione (GSH) levels [16] and regulate 1-Cys peroxiredoxin activity [15]. Accordingly, our results revealed that ascorbic acid lowered the lipid peroxidation level, increased the GSH/GSSG ratio and trehalose content, and induced glutathione reductase (GR) activity, but did not protect protein against carbonylation. There-
A

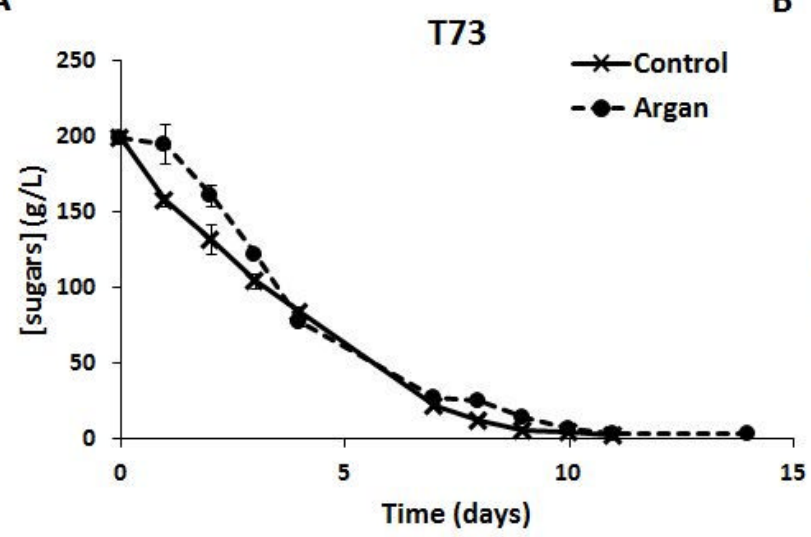

C
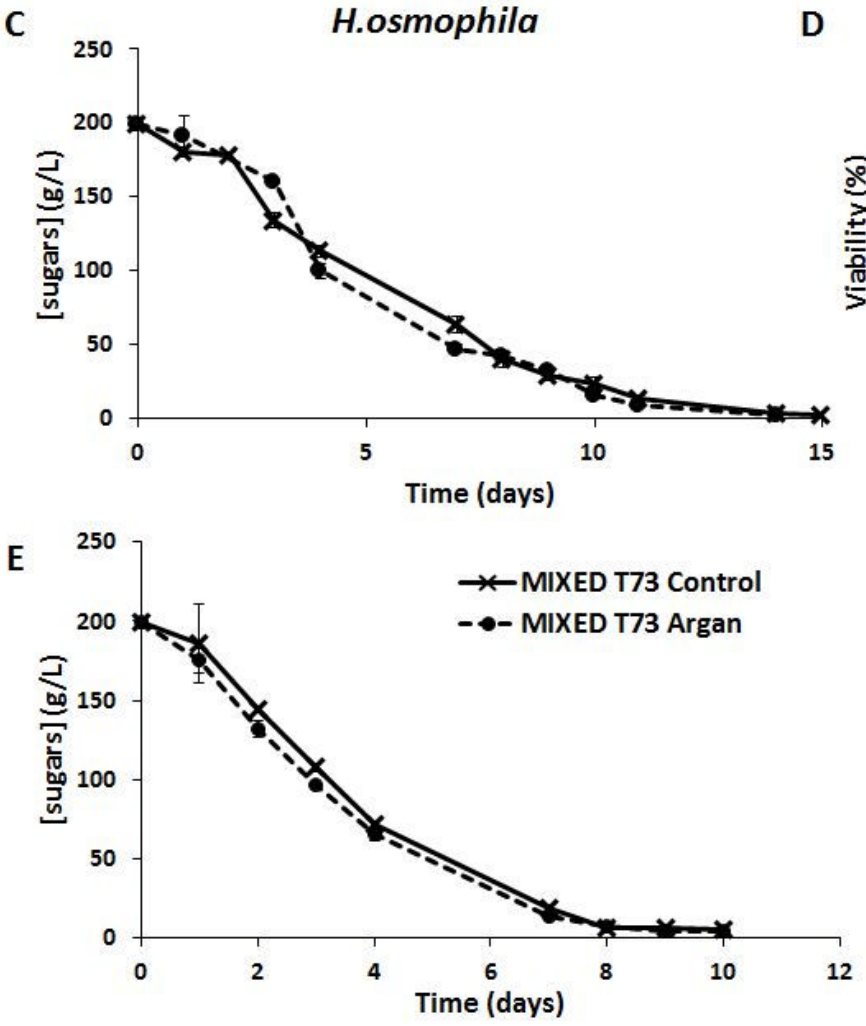

B
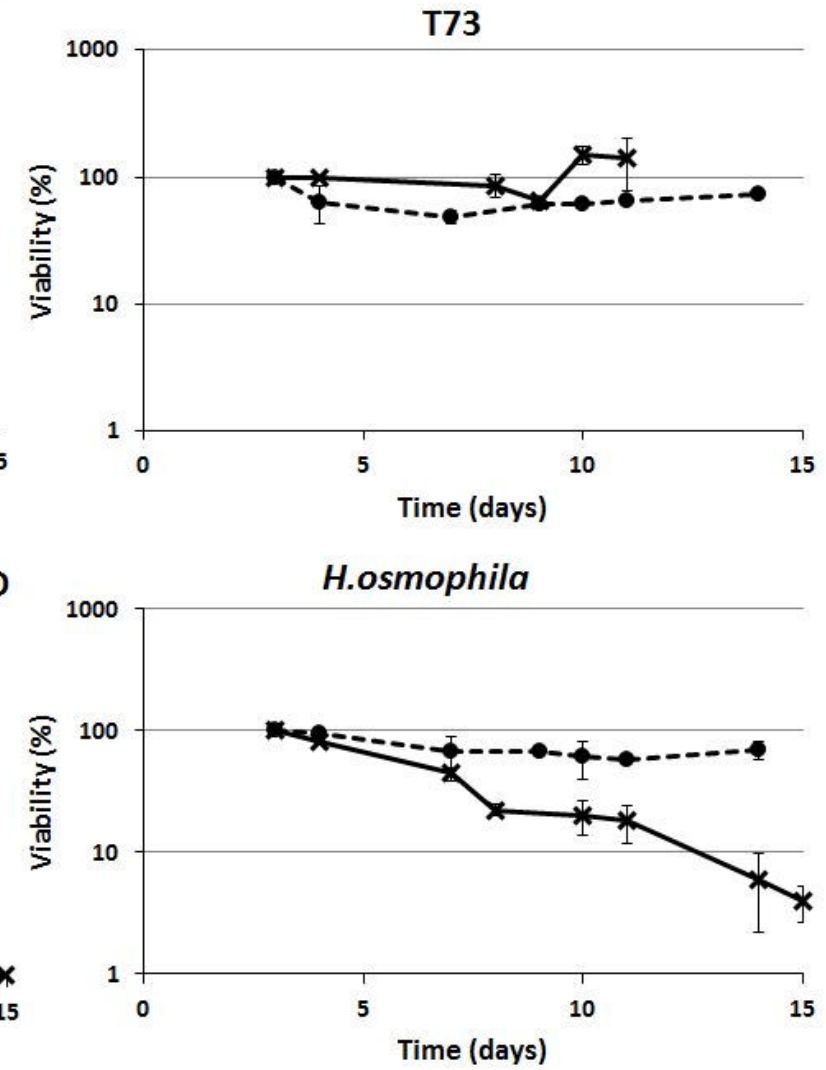

FIGURE 5: Fermentation parameters for vinifications with T73 and $\boldsymbol{H}$. osmophila pure cultures and with mixed cultures. Sugar consumption ( $A$ and $\mathbf{C}$ ) and viability (B and D) profiles during natural must fermentation inoculated with the ADY obtained from molasses in the absence (control) and presence of argan oil (argan). Panel E shows sugar consumption in vinifications conducted by mixed starters where $S$. cerevisiae T73 ADY was obtained from molasses in the absence (control) or presence of argan oil (argan) and the H. osmophila ADY was always obtained from molasses supplemented with argan oil. Fermentations were considered complete when the sugars concentration went below $2 \mathrm{~g} / \mathrm{L}$. 
TABLE 4. Enological parameters and volatile compounds in the wines obtained by monocultures and multi-starter mixed fermentations using the ADY obtained with the standard molasses (control) and the molasses supplemented with argan oil (argan).

\begin{tabular}{|c|c|c|c|c|c|c|c|}
\hline & & \multicolumn{6}{|c|}{ Fermentation } \\
\hline & & \multicolumn{2}{|c|}{ T73 } & \multicolumn{2}{|c|}{ H. osmophila } & \multicolumn{2}{|c|}{ Mixed } \\
\hline & & Control & Argan & Control & Argan & Control & Argan \\
\hline \multirow{3}{*}{$\begin{array}{l}\text { Enological parameters } \\
\qquad(\mathrm{g} / \mathrm{L})\end{array}$} & Ethanol & 10.06 & 11.33 & 10.56 & 10.94 & 11.67 & 12.63 \\
\hline & Glycerol & 10.55 & 9.39 & 9.44 & 9.45 & 8.39 & 8.81 \\
\hline & Acetic acid & 0.14 & 0.004 & 0.31 & 0.05 & 0.19 & 0.18 \\
\hline \multirow{4}{*}{ Acetate esters (mg/L) } & Ethyl acetate & 36.39 & 36.75 & 111.73 & 87.79 & 60.63 & 49.96 \\
\hline & Isobutyl acetate & 0.05 & 0.05 & 0.05 & 0.08 & nd* & nd* \\
\hline & Isoamyl acetate & 0.72 & 0.78 & 0.76 & 1.62 & 0.68 & 0.68 \\
\hline & 2-phenyl-ethyl & 0.25 & 0.43 & 7.71 & 16.36 & 0.340 & 0.22 \\
\hline \multirow{3}{*}{$\begin{array}{l}\text { Higher alcohols } \\
\qquad(\mathrm{mg} / \mathrm{L})\end{array}$} & 2-phenylethanol & 39.42 & 73.67 & 23.41 & 62.33 & 95.56 & 68.53 \\
\hline & Isobutyl & 59.15 & 61.55 & 52.17 & 76.18 & 73.90 & 57.69 \\
\hline & Isoamyl alcohol & 292.0 & 302.74 & 184.28 & 330.53 & 366.83 & 318.13 \\
\hline \multirow{3}{*}{$\begin{array}{l}\text { Fatty acid esters } \\
\qquad(\mathrm{mg} / \mathrm{L})\end{array}$} & Ethyl caprylate & 0.280 & 0.27 & 0.02 & 0.26 & 0.09 & 0.07 \\
\hline & Ethyl caprate & 0.03 & 0.05 & 0.12 & 0.43 & 0.06 & 0.05 \\
\hline & Caproate & 0.33 & 0.32 & 0.03 & 0.31 & 0.16 & 0.13 \\
\hline
\end{tabular}

*nd: not detected.

The average error in the chromatographic measurements was less than $5 \%$ in all cases.

fore, the stimulation of glycolysis and reduction of oxidative damage would increase biomass yield.

Oleic and caffeic acids supplementation exhibited the same effects on biomass yield and oxidative response by reducing lipid peroxidation, but not protein carbonylation. Oleic acid supplementation has been used in wine yeast to mitigate oxidative stress during must fermentation because the lipid composition of cell membranes affects the activities of membrane-associated enzymes and transporters [21]. The use of oleic acid and glucose co-substrates has been recently found to increase biomass production by reducing the Crabtree effect [37]. Oleic acid would lead to an increase of biomass production by reducing ethanol production because of increased tricarboxylic acid cycle activity and, therefore, global respiratory capacity. This effect would enhance biomass yield, but not fermentative capacity, which agrees with our results. Moreover, it has been found that accumulation of fatty acids allows an adaptation to the endogenous oxidative stress associated with higher levels of reduced glutathione [38], which is also consistent with our results. Finally, caffeic acid has been linked with apoptosis and anticancer and antifungal activities [16] and, at low doses, diminishes lipid peroxidation and blocks ROS due to activation of the cell wall integrity (CWI) pathway $[39,40]$ and GSH homeostasis regulation [41].
Based on antioxidant molecules supplementation, we conclude that low fermentative capacity is inherent for the Candida, Pichia and Hanseniaspora species and is not related mainly to oxidative stress. However, low biomass yield correlates with low oxidative defense in association with deficient GSH synthesis.

Nevertheless, as the use of pure chemicals could prove controversial in food industries, we propose food-grade argan oil supplementation during biomass propagation for wine ADY production. Argan oil contains high levels of linoleic and oleic acids, and is rich in polyphenols and tocopherols, which exhibit significant antioxidant activity [24]. Minor compounds, such as sterols, carotenoids, caffeic acid, ascorbic acid, and squalene, contribute to its nutritional, dietetic and organoleptic value, and also to its preservative and health properties [25]. In this case, argan oil improved the fermentative capacity in the $C$. stellata and Hanseniaspora species, but did not increase biomass yields. Moreover, it significantly reduced lipid peroxidation, increased the GSH/GSSG ratio, raised trehalose levels, and modulated the activity of enzymatic activities such as GR and catalase. The beneficial effect of argan oil on fermentative capacity could be also mediated by preventing membrane damage, increasing unsaturated fatty acids levels and elevating membrane permeability [42]. Therefore, the low fermentative capacity of non-Saccharomyces yeasts, 
such as Hanseniaspora species, could be improved by modulating membrane permeability. Moreover, argan oil supplementation in molasses during ADY production improved yeast viability and reduced fermentation times in the natural must vinifications inoculated with both pure culture and mixed starters, and did not affect the organoleptic and sensorial properties of the resulting wine. However, the effects on volatile compounds levels were more diverse and further studies are still necessary to adjust the relationship between non-Saccharomyces and Saccharomyces species in multi-starter fermentations.

\section{MATERIALS AND METHODS}

\section{Strains and cultivation conditions}

Six wine yeast strains were studied: the well-known commercial S. cerevisiae strain T73, which was used as a control [43], and five non-Saccharomyces wine yeast species, which were classified into three groups: (1) largely aerobic yeasts: Candida stellata from the Yeast Genetic Stock Center (SC 5314) and Pichia fermentans from the Centraalbureau voor Schimmelcultures, Fungal and Yeast Collection (CBS 7435); (2) apiculate yeasts with low fermentative activity, Hanseniaspora osmophila (CECT 1474) and Hanseniaspora guilliermondii (CECT 11027) from the Spanish Type Culture Collection (CECT); (3) the highly efficient fermentative yeast Torulaspora delbrueckii from Lallemand Inc. (D91).

Precultures and molasses for the biomass propagation and YPGF medium for the fermentative capacity assays were prepared as previously described [30].

For the antioxidants treatments, the molasses medium was supplemented with $50 \mu \mathrm{M}$ ascorbic acid, $5 \mu \mathrm{M}$ caffeic acid or $6 \mathrm{mg} / \mathrm{mL}$ oleic acid. Argan oil was added at the ratio of $1: 100(\mathrm{v} / \mathrm{v})$ to provide a final concentration of $6 \mathrm{mg} / \mathrm{mL}$ oleic acid in molasses [14].

\section{Biomass dehydration and rehydration conditions}

Dehydration and rehydration procedures at laboratory scale were previously tested and compared to industrial practices [10]. Yeast biomass was separated from the molasses medium by centrifugation at $3000 \mathrm{rpm}$ and subjected to several washing steps with cold distilled water. The concentrated biomass (500 mg) was spread on open Petri dishes and dehydrated in an air flux inside an oven at $30^{\circ} \mathrm{C}$ for $24 \mathrm{~h}$ to reach approximately $8 \%$ relative humidity, as determined by weight loss, and dried biomass was kept at room temperature. For rehydration, distilled water was used to resuspend the dried biomass at $37^{\circ} \mathrm{C}$ for $10 \mathrm{~min}$ under static conditions, followed by $10 \mathrm{~min}$ with shaking at $140 \times \mathrm{g}[10,28,44]$.

\section{Pure culture and mixed vinifications}

For the vinification experiments with pure cultures, Tempranillo must (Bodegas J. Belda, Fontanars dels Alforins, 2013) was sterilized with $0.2 \%(\mathrm{v} / \mathrm{v})$ dimethyl dicarbonate for $48 \mathrm{~h}$ at $4^{\circ} \mathrm{C}$. Sterile bottles that contained $30 \mathrm{~mL}$ of must were inoculated with the rehydrated biomass of $\mathrm{S}$. cerevisiae T73 or $\mathrm{H}$. osmophila, previously obtained by growth in standard molasses (control) or argan oil-supplemented molasses (argan) to an $\mathrm{OD}_{600}$ of 0.1 . These bottles were incubated at $28^{\circ} \mathrm{C}$ with gentle agitation (125 rpm) without aeration until complete sugar consumption.
For the vinification experiments with mixed starters, sterile bottles that contained $20 \mathrm{~mL}$ of natural must were simultaneously inoculated with S. cerevisiae T73 ADY from the control molasses and the argan oil-supplemented molasses, and $H$. osmophila from the argan oil-supplemented molasses. T73 and $H$. osmophila were inoculated at $\mathrm{OD}_{600} 0.1$ and $\mathrm{OD}_{600} 1$, respectively.

All the vinification experiments were performed in triplicates.

\section{Viability measurement}

Appropriate dilutions of the monoculture vinifications, using the ADY from the control molasses and the argan oilsupplemented molasses, were grown on YPD plates for $24 \mathrm{~h}$ at $30^{\circ} \mathrm{C}$ and colony-forming units (CFU) were counted. Survival percentage was calculated by taking maximum day of growth as $100 \%$.

\section{Fermentative capacity measurement}

Fresh cells and dry cells were rehydrated and inoculated $\left(10^{7}\right.$ cells $\left./ \mathrm{mL}\right)$ in YPGF medium, as described elsewhere [45]. $\mathrm{CO}_{2}$ production was measured at 10-minute intervals for $6 \mathrm{~h}$ in a Fermograph (ATTO Corporation, Japan). Fermentative capacity was expressed as $\mathrm{mL}$ of $\mathrm{CO}_{2}$ produced per $10^{7}$ cells. Experiments were carried out in triplicates.

\section{Glutathione and intracellular trehalose determination}

Extracts were obtained from $100 \mathrm{mg}$ of cells, and were used for glutathione and trehalose determination, as previously described [10, 11, 46, 47]. The amount of glutathione was expressed as nmol per $\mathrm{mg}$ of cells. The amount of trehalose is given as $\mu \mathrm{g}$ of trehalose per $\mathrm{mg}$ of dry cell weight. Experiments were carried out in triplicates.

\section{Catalase and glutathione reductase activities}

Extracts were obtained from $50 \mathrm{mg}$ of cells and assayed spectrophotometrically as described by Jakubowski and colleagues [48] for catalase activity, and as described by Murshed and colleagues [49] for glutathione reductase activity (GR). Catalase activity was expressed as $\mu \mathrm{mol}$ of $\mathrm{H}_{2} \mathrm{O}_{2} \mathrm{~min}^{-1} \mathrm{mg}$ of pro$\operatorname{tein}^{-1}(\mathrm{U} / \mathrm{mg}$ prot). GR activity was expressed as $\mu \mathrm{mol}$ of GSSG $\mathrm{min}^{-1} \mathrm{mg}$ of protein ${ }^{-1}(\mathrm{U} / \mathrm{mg}$ prot).

\section{Protein carbonylation measurements}

The protein carbonylation in crude extracts was measured by dinitrophenilhydrazine (DNPH) derivatization and Western immunodetection of protein-bound 2,4dinitrophenylhydrazones, as previously described $[9,50]$. The anti-2,4-dinitrophenol antibody (Sigma) was used at the $1 / 3500$ dilution and the secondary antibody (goat anti-rabbit HRP conjugated, Amersham) was used at the 1/5000 dilution. The signals in blots were visualized using Lumigen TMA-6 (Amersham), images were captured with the Las1000 software (FujiFilm) and protein carbonylation was measured by an image analysis using the QuantityOne software (BioRad).

\section{Lipid peroxidation measurements}

Lipid peroxidation quantification was carried out by running a reaction of thiobarbituric acid with the malondialdehyde (MDA) product of oxidized fatty acid breakage, as previously 
described [10]. Lipid peroxidation was expressed as pmoles of MDA mg of cells ${ }^{-1}$.

Reducing sugar, ethanol, acetate and glycerol measurements Reducing sugars during fermentation were measured by a reaction to DNS (dinitro-3,5-salycilic acid) [51]. Ethanol, acetate and glycerol were measured with the kits provided by $r$ Biopharm following the manufacturer's instructions.

\section{Volatile compounds measurements}

Gas chromatography allowed the final wine volatiles to be analyzed, which was performed in a capillary gas chromatograph, Hewlett-Packard model 5890 series II, controlled with a Science TRACE GC Ultra gas Chemstation 3365, equipped with a detector FID flame ionization and provided with a capillary column HP-INNOWax $30 \mathrm{~m}$ long, $0.25 \mathrm{~mm}$ internal diameter and 0.1 .mu.m thick phase. $1.5 \mathrm{~mL}$ of sample from the end of the fermentations was used, with $0.35 \mathrm{~g}$ of $\mathrm{NaCl}$ and $20 \mathrm{~mL}$ of 2-heptanone $0.005 \%(\mathrm{w} / \mathrm{v})$ as the internal standard. The samples analyses were performed in triplicates.

\section{Statistical analysis}

Sample averages were compared using a Student's $t$-test. The samples denoted (a) were significantly different from those labeled (b) with a $p<0.05$, and also differed from those denoted (c) with a $p<0.05$. The samples labeled (ab) were not significantly different from (a) and (b), but significantly differed from (c). The samples denoted $\left({ }^{*}\right)$ were significantly different from one another.

A multivariate analysis (general linear model) assessed the effect of supplementation with different antioxidants and strains on the oxidative stress parameters (biomass propagation, fermentation capacity, lipid peroxidation, protein carbonylation, protective metabolites and enzymatic activities). The results were statistically compared by using 2-way ANOVA and the Tukey HSD post hoc tests. Statistical hypothesis tests were used to check the null hypotheses $(\alpha=.05)$ (SPSS v22.0; IBM SPSS Inc.). A PCA (Principal Component Analysis) was generated to visualize a $2 \mathrm{D}$ plot of the first two principal com-

\section{REFERENCES}

1. Zott K, Miot-Sertier C, Claisse O, Lonvaud-Funel A, MasneufPomarede I (2008). Dynamics and diversity of non-Saccharomyces during the early stages in winemaking. Int J Food Microbiol 125:197203. doi: 10.1016/j.ijfoodmicro.2008.04.001

2. Ciani M, Comitini F, Mannazzu I, Domizio P (2010). Controlled mixed culture fermentation: a new perspective on the use of nonSaccharomyces yeasts in winemaking. FEMS Yeast Res 10:123-133. doi: 10.1111/j.1567-1364.2009.00579.x

3. Dashko S, Zhou N, Tinta T, Sivilotti P, Lemut MS, Trost K, Gamero A, Boekhout T, Butinar L, Vrhovsek U, Piskur J (2015). Use of nonconventional yeast improves the wine aroma profile of Ribolla Gialla. J Ind Microbiol Biotechnol 42:997-1010. doi: 10.1007/s10295-0151620-y

4. Renault PE, Albertin W, Bely M (2013). An innovative tool reveals interaction mechanisms among yeast populations under oenological conditions. Appl Microbiol Biotechnol 97:4105-4119. doi: 10.1007/s00253-012-4660-5

5. Andorra I, Berradre M, Rozes N, Mas A, Guillamon JM, EsteveZarzoso $B$ (2010). Effect of pure and mixed cultures of the main wine ponents, which revealed potential grouping patterns among supplementations or facilitated the recognition of outlier groups using the PAST 3.05 statistical software package [52].

\section{ACKNOWLEDGEMENTS}

We are grateful to Lallemand Inc. for providing the $T$. delbrueckii strain from its collection. This work has been supported by grants AGL2011-24353 and AGL2014- AGL201452984-R from the Spanish Ministry of Economy and Competitiveness (MINECO) to E.M, and it was performed as part of the Programme VLC/Campus, Microcluster IViSoCa (Innovation for a Sustainable Viticulture and Quality), and Microcluster BBLM (Model Yeasts in Biomedicine \& Biotechnology). E.G-S. was a predoctoral fellow of the JAE program and R.G-P. was a predoctoral fellow of the I3P program, both from the CSIC (Spanish National Research Council). Professional English edition has been done by Helen L Warburton (hya@telefonica.net).

\section{CONFLICT OF INTEREST}

The authors declare no commercial or financial conflict of interest.

\section{COPYRIGHT}

(C) 2018 Gamero-Sandemetrio et al. This is an open-access article released under the terms of the Creative Commons Attribution (CC BY) license, which allows the unrestricted use, distribution, and reproduction in any medium, provided the original author and source are acknowledged.

Please cite this article as: Esther Gamero-Sandemetrio, Lucía Payá-Tormo, Rocío Gómez-Pastor, Agustín Aranda and Emilia Matallana (2018). Non-canonical regulation of glutathione and trehalose biosynthesis characterizes non-Saccharomyces wine yeasts with poor performance in active dry yeast production. Microbial Cell 5(4): 184-197. doi: 10.15698/mic2018.04.624

yeast species on grape must fermentations. Eur Food Res Technol 231:215-224. doi: 10.1016/j.fm.2008.05.005

6. Capece A, Siesto G, Poeta C, Pietrafesa R, Romano P (2013). Indigenous yeast population from Georgian aged wines produced by traditional "Kakhetian" method. Food Microbiol 36:447-55. doi: 10.1016/j.fm.2013.07.008

7. Romano P, Fiore C, Paraggio M, Caruso M, Capece A (2003a). Function of yeast species and strains in wine flavour. Int J Food Microbiol 86:169-180. PMID: 12892932

8. Pérez-Torrado R, Gómez-Pastor R, Larsson C, Matallana E (2009). Fermentative capacity of dry active wine yeast requires a specific oxidative stress response during industrial biomass growth. Appl Microbiol Biotechnol 81:951-960. doi: 10.1007/s00253-008-1722-9

9. Gómez-Pastor R, Pérez-Torrado R, Cabiscol E, Ros J, Matallana E (2012) Reduction of oxidative cellular damage by overexpression of the thioredoxin TRX2 gene improves yield and quality of wine yeast dry active biomass. Microb Cell Fact 11:4. doi: 10.1186/1475-2859-114 
10. Garre E, Raginel F, Palacios A, Julien A, Matallana E (2010). Oxidative stress responses and lipid peroxidation damage are induced during dehydration in the production of dry active wine yeasts. Int J Food Microbiol 136:295-303. doi: 10.1016/j.ijfoodmicro.2009.10.018

11. Gamero-Sandemetrio E, Gómez-Pastor R, Matallana E (2014). Antioxidant defense parameters as predictive biomarkers for fermentative capacity of active dried wine yeast. Biotechnol J 9:10551064. doi: 10.1002/biot.201300448

12. Halliwell B, Gutteridge JM (2010). Antioxidants: molecules, medicines, and myths. Biochem Biophys Res Commun 393:561-564. doi: 10.1016/j.bbrc.2010.02.071

13. Escoté $X$, Miranda $M$, Menoyo $S$, Rodríguez-Porrata $B$, CarmonaGutiérrez $D$, Jungwirth $H$, Madeo $F$, Cordero RR, Mas A, Tinahones $F$, Clotet J, Vendrell J (2012). Resveratrol induces antioxidant defence via transcription factor Yap1p. Yeast. 29:251-263. doi: 10.1002/yea.2903

14. Gamero-Sandemetrio E, Torrellas M, Rábena MT, Gómez-Pastor R, Aranda A, Matallana E (2015). Food-grade argan oil supplementation in molasses enhances fermentative performance and antioxidant defenses of active dry wine yeasts. Appl Microbiol Biotechnol Express 5, 75. doi: 10.1186/s13568-015-0159-7

15. Monteiro G, Horta BB, Pimienta DP, Augusto O, Netto LES (2007). Reduction of 1-Cys peroxiredoxins by ascorbate changes the thiolspecific antioxidant paradigm, revealing another function of vitamin C. Proc Natl Acad Sci 104:4886-4891. doi: 10.1073/pnas.0700481104

16. Amari F, Fettouche A, Samra MA, Kefalas P, Kampranis SC, Makris AM (2008) Antioxidant small molecules confer variable protection against oxidative damage in yeast mutants. J Agric Food Chem 56:11740-11751. doi: 10.1021/jf802829r

17. Kimura Y, Okuda H, Okuda T, Hatano T, Agata I, Arichi S (1985). Studies on the activities of tannins and related compounds from medicinal plant and drugs. VII. Effects of extracts of leaves of Artemisia species, and caffeic acid and chlorogenic acid on lipid metabolic injury in rats fed peroxidized oil. Chem Pharm Bull 33:2028-2034. PMID: 4053225

18. Son S, Lewis BA (2002). Free radical scavenging and antioxidative activity of caffeic acid amide and ester analogues: structure-activity relationship. J Agric Food Chem 50:468-472. PMID: 11804514

19. Wu J, Omene C, Karkoszka J, Bosland M, Eckard J, Klein CB, Frenkel $\mathrm{K}$ (2011). Caffeic acid phenethyl ester (CAPE), derived from honeybee product propolis, exhibits a diversity of anti-tumor effect in preclinical models of human breast cancer. Cancer Lett 308:43-53. doi: 10.1016/j.canlet.2011.04.012

20. Ozturk G, Ginis Z, Akyol S, Erden G, Gurel A, Akyol O (2012). The anticancer mechanism of caffeic acid phenethyl ester (CAPE): review of melanomas, lung and prostate cancers. Eur Rev Med Pharmacol Sci 16:2064-2068. PMID: 23280020

21. Landolfo S, Zara G, Severino Z, Budroni M, Ciani M, Mannazzu I (2010). Oleic acid and ergosterol supplementation mitigates oxidative stress in wine strains of Saccharomyces cerevisiae. Int J Food Microbiol 141:229-35. doi: 10.1016/j.ijfoodmicro.2010.05.020

22. Avery SV, Lloyd D, Harwood JL (1995). Temperature-dependent changes in plasma-membrane lipid order and the phagocytotic activity of the amoeba Acanthamoeba castellanii are closely correlated. Biochem J 312:811-816. PMID: 8554525

23. Vigh L, Maresca B, Harwood JL (1998) Does the membrane's physical state control the expression of heat shock and other genes? Trends Biochem Sci 23:369-374. doi: 10.1016/s0968-0004(98)01279-1

24. Yaghmur A, Aserin A, Mizrahi Y, Nerd A, Garti N (2001). Evaluation of argan oil for deep-fat frying. J Food Sci Technol 34:125-144. PMID: 9810221
25. Bennani H, Drissi A, Giton F, Kheuang L, Fiet J, Adlouni A (2007). Antiprofilative effect of polyphenols and sterols of virgin argan oil on human prostate cancer cell lines. Cancer Detect Prev 31:64-69. doi: 10.1016/j.cdp.2006.09.006

26. Grant CM, Maclver FH, Dawes IW (1996). Glutathione is an essential metabolite required for resistance to oxidative stress in yeast Saccharomyces cerevisiae. Curr Genet 5:511-515. PMID: 8662189

27. Jolly NP, Varela C, Pretorius IS (2014). Not your ordinary yeast: non-Saccharomyces yeasts in wine production uncovered. FEMS Yeast Res 14: 215-37. doi: 10.1111/1567-1364.12111

28. Moreira N, Mendes F, Hogg T \& Vasconcelos I (2005). Alcohols, esters and heavy sulphur compounds production by pure and mixes cultures of apiculate wine yeasts. Int J Food Microbiol 103:285-294. doi: 10.1016/j.ijfoodmicro.2004.12.029

29. Moreira N, Mendes F, de Pinho RG, Hogg T, Vasconcelos I (2008). Heavy sulphur compounds, higher alcohols and esters production profile of Hanseniaspora uvarum and Hanseniaspora guilliermondi grown as pure and mixed cultures in grape must. Int J Food Microbiol 124:231-238. doi: 10.1016/j.ijfoodmicro.2008.03.025

30. Gómez-Pastor R, Pérez-Torrado R, Garre E, Matallana E. (2011). Recent advances in yeast biomass production. In: Matovic D (ed), Biomass-Detection, Production and Usage. InTech pp 201-222. doi: $10.5772 / 19458$

31. França MB, Panek AD, Eleutherio ECA (2007). Oxidative stress and its effects during dehydration. Comp Biochem Physiol A Mol Integr Physiol 146:621-631. doi: 10.1016/j.cbpa.2006.02.030

32. Soden A, Francis IL, Gockowiak H, Lee TH, Henschke PA (1998). The use of non-Saccharomyces yeasts in winemaking. In: Blair RJ, Sas AN Hayes PF, Høj PB, (eds). Proc 10th Aust Wine Ind Tech Conf, Sydney, Australia, pp. 166-171. Australian Wine Industry Technical Conference, Adelaide, SA, Australia.

33. Magyar I, Toth T (2011). Comparative evaluation of some oenological properties in wine strains of Candida stellata, Candida zemplinina, Saccharomyces uvarum and Saccharomyces cerevisiae. Food Microbiol 28:94-100. doi: 10.1016/j.fm.2010.08.011

34. Di Maio S, Genna G, Gandolfo V, Amore G, Ciaccio M, Oliva D (2012). Presence of Candida zemplinina in Sicilian musts and selection of a strain for wine mixed fermentations. S Afr J Enol Vitic 33:80-87. doi: 10.21548/33-1-1309

35. Jung $\mathrm{CH}$, Wells WW (1997). Ascorbic acid is a stimulatory cofactor for mitochondrial glycerol-3-phosphate dehydrogenase. Biochem Biophys Res Commun 239: 457-62. doi: 10.1006/bbrc.1997.7438

36. Sies H, Stahl W (1995). Vitamins E and C, B-carotene, and other carotenoids as antioxidants. Am J Clin Nutr 62:1315-1321. PMID: 7495226

37. Marc J, Feria-Gervasio D, Mouret JR, Guillouet SE (2013). Impact of oleic acid as co-substrate of glucose on "short" and "long-term" Crabtree effect in Saccharomyces cerevisiae. Microb Cell Fact. 12:83. doi: 10.1186/1475-2859-12-83

38. Andrisic L, Collinson E., Thehlivets O, Perak E, Zarkovic T, Dawes IW, Zarkovic N, Cipak Gasparovic A (2015). Transcriptional and antioxidative responses to endogenous polyunsatured fatty acid accumulation yeast. Mol Cell Biochem 399:27-37. doi: 10.1007/s11010-014-2229-6

39. Vilaça R, Mendes V, Mendes MV, Carreto L, Amorin MA, de Freitas $\mathrm{V}$, Moradas-Perreira P, Mateus N, Costa V (2012). Quercetin protects Saccharomyces cerevisiae against oxidative stress by inducing trehalose biosynthesis ant the cell wall integrity pathway. PloS One. 7(9):e45494. doi: 10.1371/journal.pone.0045494

40. Li Y, Chen LJ, Jiang F, Yang Y, Wang XX, Zhang Z, Li Z, Li L (2015). Caffeic acid improves cell viability and protects against DNA damage: 
involvement of reactive oxygen species and extracellular signalregulated kinase. Bra J Med Bio Res 48:502-508. doi: 10.1590/1414431X20143729

41. Paumi CM, Pickin KA, Jarrar R, Herren CK, Cowley ST (2012). Ycf1p attenuates basal level oxidative stress response in Saccharomyces cerevisiae. FEBS Lett. 586:847-853. doi: 10.1016/j.febslet.2012.02.010

42. Díaz-Hellín P, Gómez-Alonso $S$, Borrull A, Rozès N, Cordero-Otero $\mathrm{R}$, Úbeda J (2014). Membrane lipid variability in Saccharomyces cerevisiae wine strains rehydrated in the presence of metabolic activators. J Agric Food Chem 62:8679-8685. doi: 10.1021/jf500895y

43. Querol A, Barrio E, Huerta T, Ramón D (1992). Dry yeast strain for use in fermentation of Alicante wines: selection and DNA patterns. J Food Sci 57:183-185. doi: 10.1111/j.1365-2621.1992.tb05451.x

44. Pereira EJ, Panek AD, Eleutherio ECA (2003). Protection against oxidation during dehydration of yeast. Cell Stress Chaperon 8:120-124 PMID: 14627197

45. Gamero-Sandemetrio E, Gómez-Pastor R, Matallana E (2013). Zymogram profiling of superoxide dismutase and catalase activities allows Saccharomyces and non-Saccharomyces species differentiation and correlates to their fermentation performance. Appl Microbiol Biotechnol 97:4563-4576. doi: 10.1007/s00253-012-4672-1
46. Griffith OW (1980). Determination of glutathione and glutathione disulfide using glutathione reductase and 2-vynilpyridine. Anal Biochem 106:207-212. PMID: 7416462

47. Parrou JL, François J (1997). A simplified procedure for a rapid and reliable assay of both glycogen and trehalose in whole yeast cells. Anal Biochem 248:186-188. PMID: 917774

48. Jakubowski W, Bilinski T, Bartosz G (2000). Oxidative stress during aging of stationary cultures of the yeast Saccharomyces cerevisiae. Free Radic Biol Med 28:659-664. PMID: 10754260

49. Murshed R, Lopez-Lauri F, Sallanon H (2008). Microplate quantification of enzymes of the plant ascorbate-glutathione cycle. Anal Biochem 383:320-322. doi: 10.1016/j.ab.2008.07.020

50. Levine RL, Williams JA, Stadtman ER, Shacter E (1994). Carbonyl assays for determination of oxidatively modified proteins. Methods Enzymol 233:346-357. PMID: 8015469

51. Robyt JF, Whelan WJ (1972). Reducing value methods for maltodextrins. I. Chain-length dependence of alkaline 3,5dinitrosalicylate and chain-length independence of alkaline copper. Anal Biochem 45:510-516. PMID: 5060605

52. Hammer O, Harper DAT, Ryan PD (2001). Past: paleontological statistics software package for education and data analysis. Palaentol Electron 4:4-9. http://palaeo-electronica.org/2001_1/past/past.pdf. 